\title{
The Effect of Verticillium Infection in Runner Plant Propagation Nurseries on Resistant and Susceptible Strawberry Genotypes
}

\author{
Douglas V. Shaw \\ Department of Plant Sciences, University of California, Davis, CA 95616 \\ Thomas R. Gordon \\ Plant Pathology Department, University of California, Davis, CA 95616 \\ Kirk D. Larson \\ Department of Plant Sciences, University of California, Davis, CA 95616 \\ Sharon C. Kirkpatrick \\ Plant Pathology Department, University of California, Davis, CA 95616
}

\begin{abstract}
AdDitional INDEX WORDs. Verticillium dahliae, Fragaria $\times$ ananassa, soil fumigation
ABstract. Mother plants from strawberry (Fragaria $\times$ ananassa Duch.) genotypes susceptible to and resistant to verticillium (Verticillium dahliae Kleb.) were inoculated with this pathogen in a high elevation nursery. The infection rate for mother plants was $\mathbf{7 7 . 3 \%} \pm \mathbf{7 . 5 \%}$ and $\mathbf{8 0 . 7 \%} \pm \mathbf{5 . 4 \%}$ for resistant and susceptible genotypes, respectively. Conversely, the percentage of runner plants identified as infected by postharvest petiole assay that were produced by these inoculated mother plants differed significantly $(P<0.01)$ between sets of genotypes, $25.1 \% \pm 3.7 \%$ and $59.8 \% \pm 5.3 \%$ for resistant and susceptible genotypes, respectively. The percentage of runner plants from inoculated mothers that eventually collapsed in the fruit production field was larger than the percentage identified as infected by petiole assay for susceptible genotypes $(68.9 \% \pm 4.1 \%)$, and substantially less than the pre-plant infected fraction for resistant genotypes $(3.5 \% \pm$ $1.4 \%$ ). Yield for runner plants from inoculated mothers was reduced by $73 \%$ to $75 \%$ for susceptible genotypes, and by $\mathbf{7 \%}$ to $15 \%$ for resistant genotypes. The percentage of runner plants identified as infected in the nursery was correlated with the percentage of plants that collapsed in the fruiting field $(r=0.91, P<0.01)$ and with yield in infested plots $(r=$ $-0.79, P<0.01)$. Most of the effect of this disease was expressed as plant collapse, but the presence of yield reductions larger than the rate of plant collapse demonstrated substantial sub-lethal effects as well.
\end{abstract}

Widespread adoption of pre-plant soil fumigation with methyl bromide and chloropicrin (Wilhelm and Koch, 1956) together with annual planting systems (Voth and Bringhurst, 1990) have virtually eliminated severe soil infestations of $V$. dahliae in California strawberry fruit production fields (Wilhelm and Paulus, 1980; Wilhelm et al., 1974). However, significant V. dahliae infection persists in annual strawberry cultivation systems primarily through introduction of the pathogen during the final stage of propagation (Gordon et al., 2002), in high elevation nurseries (Larson and Shaw, 2000). The persistence of the problem at these locations traces to rotation with susceptible host crops (Davis et al., 1996), to sub-optimal fumigation conditions (Wilhelm and Koch, 1956), and to the longevity of $V$. dahliae micro-sclerotia in soil (Schnathorst, 1981).

Although distinct visual symptoms often develop on mother plants infected with $V$.dahliae in high elevation nurseries, infected runner plants are usually symptomless (Gordon et al., 2002). Infected runner plants may eventually collapse in fruiting fields or the disease can be expressed as sub-lethal losses in productivity (Shaw et al., 2002). Verticillium dahliae can be transmitted from an infected mother plant to daughter runner plants through stolons (Gordon et al., 2002), thus relatively low levels of field infection can result in rather high frequencies of infected runner plants at nursery harvest.

Received for publication 25 May 2005. Accepted for publication 26 June 2005. The authors wish to thank Lassen Canyon Nursery for their generous assistance in conducting the nursery phases of this research.
Breeding for resistance to $V$. dahliae has been suggested frequently as a solution to problems caused by verticillium wilt in California (Bringhurst et al., 1961, 1968). Progress has been made in identifying and utilizing genetic variation for resistance in the University of California (UC) breeding population (Shaw et al., 1996, 1997; Shaw and Gordon, 2003). Standard resistance evaluations for this disease depend on individual plant inoculations (Shaw et al., 1996) and the resistance ratings obtained using these methods have been demonstrated to correspond with those obtained in soils infested with $V$. dahliae micro-sclerotia (Gordon et al., 2005). However, the relative performance of resistant and susceptible genotypes has not been evaluated using nursery inoculation systems, thus our ability to predict the performance of genotypes identified as resistant under controlled screening conditions in commercial propagation systems is limited.

The objective of our study was to compare sets of strawberry genotypes identified as resistant and susceptible for patterns of mother plant and runner plant infection in an inoculated high elevation nursery. The runner plants from this nursery were further evaluated for disease symptoms in a fruit production field and compared for productivity with non-inoculated control runner plants to determine the magnitude of lethal and sub-lethal effects of nursery infection with $V$. dahliae.

\section{Materials and Methods}

Six genotypes from the UC breeding population were used for this study. Three genotypes ('Parker', 'Camarosa', Cal 88.31-3) 
were identified as highly susceptible and three ('Laguna', Cal 94.256-607, Cal 96.267-202) were identified as moderately to highly resistant in conidial dip trials conducted previously (Shaw et al., 1996). All six genotypes derive from the Univ. of California Strawberry Improvement program, which has been essentially closed to germplasm introduction for several decades. 'Laguna' was a grandparent of Cal 96.267-202, whereas Cal 94.256-607 was unrelated to the other genotypes in the prior three generations. The inheritance of resistance in this population appears to be polygenic (Shaw et al., 1996) and no evidence for a major gene that controls resistance such as that detected in tomato (Schaible et al., 1951) has been observed.

Runner plants from each genotype were established at a high elevation nursery near Macdoel, Calif. (lat. 41.8N, elev. $\approx 1300 \mathrm{~m}$ ) in late April of 2001, 2002, and 2003. In each of the three years, runner plants of each genotype were planted in soils fumigated with 2 methyl bromide : 1 chloropicrin (w/w) at $392 \mathrm{~kg} \cdot \mathrm{ha}^{-1}$ during the spring of the planting year. A single plot of 16-26 runner plants was established for each genotype for the inoculation trials, and a second plot of 12-16 plants was established at the same location to provide non-inoculated runner plants for performance comparisons in fruiting fields. Plots intended for propagation of diseased runner plants were left untreated until mother plants were well established and had produced some fully-rooted, firstgeneration runner plants. Each mother plant was inoculated by removing soil to expose a portion of the root system, severing several roots and pouring $50 \mathrm{~mL}$ of a conidial suspension of $V$. dahliae $\left(2.5 \times 10^{6}\right.$ conidia $\left./ \mathrm{mL}\right)$ over the wounded roots. Inoculations were conducted on 11, 16, and 11 July, for the 2001, 2002, and 2003 trials, respectively.

Preharvest assays for $V$. dahliae were performed for all inoculated mother plants on 7, 11, and 17 Sept. for the 2001, 2002, and 2003 trials, respectively; using a single petiole from each plant and isolation procedures described previously (Gordon et al., 2002). Average infection percentages for mother plants were calculated for individual genotypes over years and the variation over genotypes used to calculate a sample SE for each resistance category. Runner plants were harvested from all inoculated and control plots on 14 Oct. in all 3 years, trimmed to remove all leaves (commercial standard), and stored at $1^{\circ} \mathrm{C}$ until planting in fruiting field trials. Individual lots were processed on separate benches and runners from non-inoculated treatments were processed prior to those from inoculated sources to avoid cross contamination. A single petiole was sampled from 81-103 runner plants from each genotype in each year on 21-22 Oct. in all years, V. dahliae isolations were conducted (Gordon et al., 2002), and the average percentage infection and a sample SE were obtained over the three trial years. Differences among genotypes for mother plant and runner plant infection percentage were determined using twoway analyses of variance (ANOVA) with years and genotypes as sources of variation.

Performance trials were established using inoculated and control sources of high elevation runner plants near Watsonville, Calif. (lat. $36^{\circ} 54^{\prime} \mathrm{N}$, long. $121^{\circ} 48^{\prime} \mathrm{W}$ ) on 23 Oct. of each year and treated according to recommendations for annual commercial winter planting systems (Welch, 1989). Experiments were conducted on two-row raised beds with $1.32-\mathrm{m}$ centers and $0.36-\mathrm{m}$ in-row plant spacing. Four replicates, each containing a single plot of 20 runner plants per genotype, were established in each year for each inoculation treatment. The plants established in fruiting field trials were a subset of those assayed for $V$. dahliae infection immediately after nursery harvest. Fruit yield for both inoculated and control runner plants was recorded weekly for 21 to 24 consecutive weeks during the spring and summer following planting in each trial year, with harvest initiated the first or second week of April. ANOVA for seasonal yield was performed with years, replicates nested in years, inoculation treatment, genotypes and their interactions as random effects and components of variance were calculated for all sources related to $V$. dahliae infection. All ANOVAs were conducted using SAS procedure GLM and variance components were obtained using SAS procedure VARCOMP (SAS Institute, 1988).

The percentage of plants severely stunted or collapsed in fruit production trials, henceforth referred to as the percentage collapsed, was recorded for individual plots in the Watsonville trial on four to five dates each year, beginning when severe stunting was present in the most susceptible genotypes. Scoring was initiated on 22 Apr. 2002, 19 Mar. 2003, and 6 Apr. 2004 for the three trials, respectively, and continued at $\approx 3$-week intervals. A plant collapse score was compiled by averaging the percentage of severely stunted or collapsed plants over all scoring dates and this average percentage of collapsed plants was used as an index of the severity of infection during the fruit production season. This average percentage was slightly less than the total number of collapsed plants, but was used to enhance correspondence between field plant collapse, which continued somewhat throughout the fruit harvest season, and fruit productivity. Further resolution of the differences among resistance types was obtained by estimating correlation coefficients for infection and productivity variables using SAS Procedure CORR.

\section{Results and Discussion}

The percentages of mother plants infected in the nursery were similar regardless of genotypic resistance category, but large differences were detected for the percentage of infected runners produced by susceptible and resistant sets of genotypes (Table $1)$. Over the three trial years, $80.7 \%( \pm 5.4 \%)$ and $77.3 \%( \pm 7.5 \%)$ of the mother plants were identified as infected by petiole assay for susceptible and resistant genotypes, respectively; the corresponding infection percentages for runner plants produced by these inoculated mother plants were $59.8 \%( \pm 5.3 \%)$ and $25.1 \%$ $( \pm 3.7 \%)$ for susceptible and resistant genotypes. Consistent with these observations, ANOVAs detected no significant differences among genotypes for mother plant infection level, but did detect highly significant $(P<0.01)$ differences among genotypes for the percentage infection of their runner plants (Table 2 ). The variation in percentage infection observed over years was highly significant $(P<0.01)$ for mother and runner plant infection (Table 2$)$, despite identical inoculation procedures and genetic materials.

The differences observed between genotypic resistance categories for the percentage of infected runner plants were amplified in the fruiting field (Table 1). For susceptible genotypes, the percentage of runner plants that collapsed in the fruiting field was larger than the percentage identified as infected in pre-plant assays $(68.9 \% \pm 4.1 \%$ vs. $59.8 \% \pm 5.3 \%)$. This observation suggests that some of the runner plants tested immediately after nursery harvest were infected with $V$. dahliae, but could not be detected by the petiole assay. Conversely, the percentage of runner plants from resistant genotypes that collapsed in the fruiting field was substantially less than the percentage detected by pre-plant petiole assay $(3.5 \% \pm 1.4 \%$ vs. $25.1 \% \pm 3.7 \%)$. Thus most of the runner plants from resistant genotypes identified as infected by pre-plant petiole assay never expressed visual disease symptoms 
Table 1. Average percentage infection $( \pm \mathrm{SE})$ for Verticillium dahliae-inoculated strawberry mother plants and their daughter runner plants evaluated prior to establishment in fruiting field trials from susceptible and resistant genotypes.

\begin{tabular}{|c|c|c|c|c|}
\hline \multirow[b]{2}{*}{ Trial year } & \multirow[b]{2}{*}{$\begin{array}{l}\text { Genotypic } \\
\text { category }\end{array}$} & \multicolumn{3}{|c|}{ Percentage infected/collapsed } \\
\hline & & $\begin{array}{c}\text { Nursery mother } \\
\text { plants }\end{array}$ & $\begin{array}{c}\text { Nursery } \\
\text { runner plants }\end{array}$ & $\begin{array}{l}\text { Fruiting field } \\
\text { runner plants }\end{array}$ \\
\hline \multirow[t]{2}{*}{$\overline{2001}$} & Susceptible & $81.4( \pm 5.7)$ & $45.8( \pm 5.8)$ & $60.8( \pm 5.6)$ \\
\hline & Resistant & $87.6( \pm 3.2)$ & $22.8( \pm 5.6)$ & $1.6( \pm 0.5)$ \\
\hline \multirow[t]{2}{*}{2002} & Susceptible & $63.5( \pm 5.0)$ & $55.7( \pm 4.4)$ & $64.9( \pm 6.2)$ \\
\hline & Resistant & $48.6( \pm 5.6)$ & $19.3( \pm 2.3)$ & $2.5( \pm 0.8)$ \\
\hline \multirow[t]{2}{*}{2003} & Susceptible & $97.3( \pm 1.4)$ & $78.0( \pm 2.5)$ & $81.0( \pm 4.5)$ \\
\hline & Resistant & $95.7( \pm 1.0)$ & $33.3( \pm 8.4)$ & $6.3( \pm 3.8)$ \\
\hline
\end{tabular}

Table 2. ANOVA results for percentage infection in Verticillium dahliaeinoculated strawberry mother plants and their daughter runner plants evaluated prior to establishment in fruiting field trials from susceptible and resistant genotypes.

\begin{tabular}{lrcc}
\hline & & \multicolumn{2}{c}{ Mean squares } \\
\cline { 3 - 4 } Source & df & $\begin{array}{c}\text { Percent infected } \\
\text { mother plants }\end{array}$ & $\begin{array}{c}\text { Percent infected } \\
\text { runner plants }\end{array}$ \\
\hline Year & 2 & $2591.4^{* *}$ & $797.0^{* *}$ \\
Genotype & 5 & 43.3 & $1146.1^{* *}$ \\
Error & 10 & 77.6 & 104.2
\end{tabular}

*** Significant at $P<0.01$.

Table 3. ANOVA results for percentage collapse in runner plants from Verticillium. dahliae inoculated nursery plots evaluated in spring after establishment in fruiting field trials from susceptible and resistant strawberry genotypes.

\begin{tabular}{lrc}
\hline Source & df & $\begin{array}{c}\text { Mean squares for percentage } \\
\text { collapsed runner plants }\end{array}$ \\
\hline Year $(Y)$ & 2 & $41.9^{*}$ \\
Replication/Year & 9 & 1.5 \\
Genotype $(\mathrm{G})$ & 5 & $625.8^{* *}$ \\
Y $\times \mathrm{G}$ & 10 & $8.5^{* *}$ \\
Error & 45 & 1.8 \\
\hline
\end{tabular}

*,**Significant at $P<0.05$ or 0.01 , respectively.

in the fruiting field. These differences between genotypes from resistant and susceptible categories were reflected in a highly significant variance among genotypes for the percentage of runner plants from inoculated treatments that collapsed in the fruiting field (Table 3). Variance in the percentage of collapsed plants due to years $\times$ genotypes interaction was also highly significant, suggesting some inconsistency of reaction over years, but the variance components estimated for these sources $\left(\sigma^{2}{ }_{\mathrm{G}}=51.4\right.$ and $\sigma_{Y \times G}^{2}=1.67$ ) demonstrates that nearly all of the genetic differences observed for plant symptoms in the fruiting field were stable over years.

Seasonal yield was reduced by $73 \%$ to $75 \%$ for susceptible genotypes and by $7 \%$ to $15 \%$ for resistant genotypes when runner plants from inoculated mothers were compared to those propagated from non-inoculated controls (Table 4). Most of the yield reduction observed was attributable to plant collapse. However, the percent reduction in seasonal yield was larger than the percentage of collapsed plants for susceptible and resistant genotypes, demonstrating substantial sub-lethal effects of $V$. dahliae. For resistant genotypes, the percent yield reduction due to infection was 2.4-4.4 times as large as the observed percentage of collapsed plants, suggesting that sub-lethal effects are the most important contributor to yield reduction for these genotypes. The importance of variable resistance to V. dahliae for yield was
Table 4. Average yield ( \pm SE) for Verticillium dahliae- inoculated and control strawberry runner plants evaluated in fruiting field trials from susceptible and resistant genotypes.

\begin{tabular}{|c|c|c|c|}
\hline \multirow[b]{2}{*}{ Trial year } & \multirow[b]{2}{*}{ Category } & \multicolumn{2}{|c|}{ Yield (g/plant) } \\
\hline & & $\begin{array}{l}\text { Control runner } \\
\text { plants }\end{array}$ & $\begin{array}{c}\text { Inoculated } \\
\text { runner plants }\end{array}$ \\
\hline \multirow[t]{2}{*}{2001} & Susceptible & $1321( \pm 64)$ & $519( \pm 46)$ \\
\hline & Resistant & $1806( \pm 124)$ & $1728( \pm 91)$ \\
\hline \multirow[t]{2}{*}{2002} & Susceptible & $1111( \pm 50)$ & $292( \pm 46)$ \\
\hline & Resistant & $1261( \pm 167)$ & $1122( \pm 148)$ \\
\hline \multirow[t]{2}{*}{2003} & Susceptible & $1847( \pm 110)$ & $389( \pm 50)$ \\
\hline & Resistant & $1598( \pm 109)$ & $1282( \pm 110)$ \\
\hline
\end{tabular}

Table 5. ANOVA results for yield from strawberry runner plants grown at high elevation and evaluated in spring after establishment in fruiting field trials with and without nursery infestation with Verticillium dahliae.

\begin{tabular}{|c|c|c|}
\hline Source & $\mathrm{df}$ & Mean squares for yield \\
\hline Year $(Y)$ & 2 & 2172.7 \\
\hline Replication/Year & 9 & $124.2^{* *}$ \\
\hline Inoculation treatment $(\mathrm{I})$ & 1 & $13051.6^{*}$ \\
\hline Genotype (G) & 5 & 4226.2 \\
\hline $\mathrm{Y} \times \mathrm{G}$ & 10 & 348.2 \\
\hline $\mathrm{Y} \times \mathrm{I}$ & 2 & $736.3^{*}$ \\
\hline $\mathrm{I} \times \mathrm{G}$ & 5 & $1376.5^{* *}$ \\
\hline $\mathrm{Y} \times \mathrm{I} \times \mathrm{G}$ & 10 & $121.2^{* *}$ \\
\hline Error & 99 & 19.6 \\
\hline$\sigma_{G}^{2}$ & & 109.3 \\
\hline$\sigma_{I}^{2}$ & & 153.6 \\
\hline$\sigma_{I \times G}^{2}$ & & 104.6 \\
\hline$\sigma_{Y \times I \times G}^{2}$ & & 25.4 \\
\hline
\end{tabular}

further substantiated by the presence of significant inoculation treatment $\times$ genotype interaction variance (Table 5), a parameter that reflects the genetic variation due to resistance that was consistent over trial years. A significant fraction of the phenotypic variance for yield in this experiment was also attributable to years $x$ inoculation treatment $\times$ genotype interaction $\left(\sigma^{2}{ }_{Y \times I X G}=25.4\right)$, indicating some lack of stability for this resistance mechanism, but this variance component was much smaller than the component due to inoculation treatment $\times$ genotype interaction $\left(\sigma_{\mathrm{I} \times \mathrm{G}}^{2}=\right.$ 104.6), which in this experiment reflects genetic differences for resistance that are stable over years.

Significant correlation coefficients were not detected between the percentage of mother plants infected and the percentage infection in resulting runner plants, the percentage of runner plants that collapsed in the fruiting field, or the seasonal yield of runner plants from the inoculated plots in the fruiting field (Table 6). This result is a consequence of the uniformly high infection levels of mother plants regardless of genotypic resistance class, and implies that the level of infection detected in mother plants at the nursery level may be an unreliable predictor of the fruiting field resistance potential for any specific genotype. Conversely, the percentage of runner plants infected in the nursery was well correlated with the percentage of plants that collapsed in the fruiting field and negatively correlated with yield in infected plots (Table 6).

Taken together, these observations suggest that the mechanism of resistance to $V$. dahliae in this strawberry population acts by 
Table 6. Product-moment correlations for percentage infection in Verticillium dahliae-inoculated strawberry mother plants and their daughter runner plants evaluated prior to establishment in fruiting field trials, percent collapse in the fruiting field, and seasonal yield for susceptible and resistant genotypes.

\begin{tabular}{lccc}
\hline & $\begin{array}{c}\text { Runner plant } \\
\text { infection }\end{array}$ & $\begin{array}{c}\text { Percent } \\
\text { collapse }\end{array}$ & $\begin{array}{c}\text { Seasonal } \\
\text { yield }\end{array}$ \\
\hline Mother plant infection & 0.32 & 0.16 & 0.06 \\
Runner plant infection & & $0.91^{* *}$ & $-0.79^{* *}$ \\
Percent collapse & & & $-0.85^{* *}$ \\
\hline
\end{tabular}

${ }^{* *}$ Significant at $P<0.01$.

restricting transmission through vegetative tissue rather than hypersensitive exclusion. This conclusion is consistent with the results of previous studies in which cultivars differing in susceptibility to verticillium wilt were grown in naturally infested soil (Gordon et al., 2002). The high percentage of mother plants infected in inoculated plots suggests that this resistance mechanism might not be stable when challenged with very high inoculum levels in a fruit production field or in perennial strawberry production systems. Although genotypes possessing greater resistance than those included in this trial may be generated through future breeding efforts, obtaining those that ultimately preclude infection under extreme or long-term infection conditions may be a difficult task. At present, genetic resistance in strawberry is best regarded as one component of an integrated verticillium wilt management system, where other components include efforts to reduce pest populations at all runner plant and fruit production stages.

\section{Literature Cited}

Bringhurst, R.S., P.E. Hansche, and V. Voth. 1968. Inheritance of verticillium wilt resistance and the correlation of resistance with performance traits. Proc. Amer. Soc. Hort. Sci. 92:369-375.

Bringhurst, R.S., S. Wilhelm, and V. Voth. 1961. Pathogen variability and breeding verticillium wilt resistant strawberries. Phytopathology 51:786-794.

Davis, J.R., O.C. Huisman, D.T. Westerman, S.L. Hafez, D.O. Everson, L.H. Sorensen, and A.T. Schneider. 1996. Effects of green manures on verticillium wilt in potatoes. Phytopathology 86:444-453.

Gordon, T.R., S.C. Kirkpatrick, D.V. Shaw, and K.D. Larson. 2002. Dif- ferential infection of runner plant generations by Verticillium dahliae in a high elevation strawberry (Fragaria $\times$ ananassa Duch.) nursery. HortScience 37:932-935.

Gordon, T.R., D.V. Shaw, and K.D. Larson. 2005. Comparative response of strawberries to conidial root-dip inoculations and and infection by soilborne microsclerotia of Verticillium dahliae Kleb. HortScience 40:1398-1400.

Larson, K.D. and D.V. Shaw. 2000. Soil fumigation and runner plant production: A synthesis of four years of strawberry nursery field trials. HortScience 35:642-646.

SAS Institute. 1988. SAS/STAT users guide, release 6.03 ed. SAS Inst., Cary, N.C.

Schaible, L., O.S. Cannon, and V. Waddoups. 1951. Inheritance of resistance to verticillium wilt in a tomato cross. Phytopathology 41:986-990.

Schnathorst, W.C. 1981. Life cycle and epidemiology of Verticillium, p. 81-144. In: M.E. Mace, A.A. Bell, and C.H. Beckman (eds.). Fungal wilt disease of plants. Academic, London.

Shaw, D.V., W.D. Gubler, K.D. Larson, and J. Hansen. 1996. Genetic variation for field resistance to Verticillium dahliae evaluated using genotypes and segregating progenies of California strawberries. J. Amer. Soc. Hort. Sci. 121:625-628.

Shaw, D.V., W.D. Gubler, J. Hansen, and K.D. Larson. 1997. Response to family selection for field resistance to Verticillium dahliae in California strawberries. J. Amer. Soc. Hort. Sci. 32:711-713.

Shaw, D.V., T.R. Gordon, and K.D. Larson. 2002. Runner plant cold storage reduces Verticillium dahliae Kleb. infection of nursery origin in strawberry (Fragaria ×ananassa Duch.). HortScience 37:932-935.

Shaw, D.V. and T.R. Gordon. 2003. Genetic reaction for resistance to verticillium wilt (Verticillium dahliae Kleb.) in strawberry (Fragaria xananassa Duch.) with two-stage family and genotypic selection. HortScience 38:432-434.

Voth, V. and R.S. Bringhurst. 1990. Culture and physiological manipulation of California strawberries. HortScience 25:889-892.

Welch, N. 1989. Strawberry production in California. Univ. of California, Coop. Ext. Lfit. 2959.

Wilhelm, S. and E.C. Koch. 1956. Verticillium wilt controlled. Calif. Agr. 10:3-14.

Wilhelm, S. and A.O. Paulus. 1980. How soil fumigation benefits the California strawberry industry. Plant Dis. 64:264-270.

Wilhelm, S., R.C. Storkan, and J.M. Wilhelm. 1974. Preplant soil fumigation with methyl bromide-chloropicrin mixtures for control of soil-borne diseases of strawberries - A summary of fifteen years of development. Agr. Environ. 1:227-236. 